\title{
Blended care; development of a day treatment program for medically unexplained physical symptoms (MUPS) in the Dutch Armed Forces
}

\author{
M.M.P. Zeylemaker ${ }^{\mathrm{a}}$, F.H.H. Linn ${ }^{\mathrm{a}}$ and E. Vermetten ${ }^{\mathrm{b}, \mathrm{c}, *}$ \\ ${ }^{a}$ Department of Defense, Central Military Hospital, Utrecht, The Netherlands \\ ${ }^{\mathrm{b}}$ Department of Defense, Military Mental Health Research, Utrecht, The Netherlands \\ ${ }^{\mathrm{c}}$ Department Psychiatry, Leiden University Medical Center, Leiden, The Netherlands
}

Received 30 July 2013

Accepted 5 February 2014

\begin{abstract}
.
BACKGROUND: A subgroup of servicemen can be identified that seek a disproportionally amount of health care in comparison to diagnostic and therapeutic perspectives. This group can be identified on the basis of an absence of a structural medical explanation for their symptoms. The symptoms manifest predominantly as fatigue and pain, and are often chronic. Patients with medical unexplained medical symptoms (MUPS) often have multiple and complex problems that would be best treated by a multidisciplinary team of medical specialists and paramedics. The military is characterized by high loyalty towards peers and leadership, leading to neglect for personal care.

OBJECTIVE: While consensus on the biological basis for these complaints is lacking, awareness on the need for effective treatments for this patient group is high.

METHOD: Based on reviews, expert recommendations and clinical demand, a specialized treatment program for soldiers with MUPS has recently been developed and implemented in the system of health care in the Netherlands Armed Forces. We developed a functional rehabilitation program with blended care elements of cognitive behavioral therapy (CBT), physical therapy, case management, and psychoeducation, embedded in a day treatment setting.

RESULTS: The program received high scores on participant as well as team satisfaction. The program is illustrated by two clinical vignettes.

CONCLUSION: The blended care program for MUPS that focused on allostatic load awareness offered a more holistic and preventive approach that contributed to a reduction of unnecessary medical consumption, and increased job participation. We recommend that the development of guidelines for diagnoses and treatment of these complaints in military settings will improve the quality of patient care, reduce disability, facilitate reintegration, and encourage scientific research.
\end{abstract}

Keywords: Multiple unexplained physical symptoms (MUPS), assessment, blended care, multidisciplinary, allostatic load, holistic approach, functional impairment

\section{Background}

${ }^{*}$ Corresponding author: E. Vermetten, Military Mental Health Research, Lundlaan 1, 3500 EZ, Utrecht, The Netherlands. Tel.: +31 30 2502591; Fax: +31 30 2502288; E-mail: hgjm.vermetten@ mindef.nl.
The reported prevalence of medical unexplained physical symptoms (MUPS) in the Dutch military population varies from $5 \%$ to $20 \%$ [1,2]. The Dutch 
Military Mental Health Care (MMHC) and the Central Military Hospital (CMH) in the Netherlands appreciated the clinical need and responsibility towards the service members to offer an effective treatment program for MUPS in the military population. The complaints are typically characterized by persistent physical symptoms such as fatigue, headaches, joint pains [3-5], and causing significant distress or functional impairment in the absence of disease or clear cause after appropriate and directed clinical assessment. MUPS are neither a disease nor have a specific diagnostic category. These non-specific symptoms have a variety of potential causes. MUPS are associated with high medical consumption [6]. This situation is not only typical for service members. Approximately two thirds of the general population experiences one or more painful or distressing symptoms in an average month, and studies show that in routine practice $25-30 \%$ of symptoms remain unexplained. Scientific and clinical investigations typically do not provide answers to the complex causal questions that arise in defining and responding to these common persistent symptoms.

Careful diagnostic assessment and treatment is of key importance for service members that may experience persistent ill-defined work-related symptoms or injuries. Rather than expanding care to exhaustive biomedical diagnostic evaluations or implementing invasive interventions or treatments targeting a narrow set of symptoms, a comprehensive approach is necessary to balance necessary diagnostic assessment and prevent unnecessary medical (over)consumption.

The objective of this paper is to: 1) present the development of a blended care program for service members with MUPS within the Dutch Department of Defense, and 2) justify the blended nature and ingredients of the program, as an intensive outpatient program. Elements of this approach are used in chronic pain centers internationally. We will describe the more holistic treatment approach to highly loyal service members with persistent, disabling ill-defined physical symptoms. The specialized care program is a multidisciplinary group treatment program that is developed for servicemen with MUPS. It is based on a treatment program, which is implemented at the Walter Reed Army Medical Center (WRAMC) in Washington, D.C., USA [3]. The specific mission of the program is to provide an intensive outpatient, multidisciplinary treatment program for people with persistent MUPS. Objectives are to help those with these symptoms and improve their quality of life, functional status, and occupational performance.

\section{Program development}

General practitioners are not always aware of illdefined conditions or MUPS, making them often hesitant to mention them [7]. Patients with MUPS symptoms are complicated for medical doctors in different ways [8]. Differences in opinions and expectations influence a doctor-patient relationship in many ways. Patients with MUPS may lack confidence in the regular healthcare system and may look for a solution in complementary or alternative treatments. When a medical diagnosis is lacking, treatment cannot be justified and targeted therapy remains absent. Referrals to external facilities often result in long delays, and lack specific understanding of military setting and demands of service. These factors contribute to the fact that undiagnosed patients feel as though they are neither understood nor cared for and as a result may feel despair. In case of external attributions, they may deplete the medical system's resources, since their attributions cannot always be corroborated. They may seek negative attention in their environment and in a public arena, such as the media. Some may develop compensation seeking behavior, yet can be stuck in a high loyalty to their employer, peer group, commander, or the military service in general. Patients typically look for acknowledgment. The authors of this paper feel that quite often there is a generalized blame directed at the army for their physical complaints, which sometimes can be reduced to specific encounters or conflicts with key persons. Finally, when a patient is referred for medical treatment, he may not feel understood by his social environment, doctor, or command line. Medical consumption is typically high in this group and characterized by an abundance of diagnostic assessments. There is often chronic functional impairment on cognitive, emotional, behavioral, and social domains. These factors contribute to disproportionally high costs for patients with MUPS in the absence of recognition of factors that can facilitate therapeutic change.

\section{Case reports}

\subsection{Case 1}

Patient is a 34-year-old captain in the Dutch Army. She was deployed in 2010 to Afghanistan. She had served the army since 1996. She felt a bit insecure because of last minute preparation (e.g. there was no time for measurement of her protective gear, which 
was given to her during the last stop over before arrival in Kandahar). These and similar experiences had made her feel a bit insecure. She was assigned a job for which she frequently had to go out of the army basecamp into unsafe areas. One occasion changed the course of her deployment. She went out to visit a children's home. On the way back they came to a crowded market. The vehicle got stuck; there were locals all around them. They were ambushed, with high threat, while she was very aware of being the only woman in an army vehicle that provided no protection in case of an ambush. The driver tried to escape by high speed driving through the crowd. During the escape, her vest was so tight that it hurt her and impeded her breathing. Because of the high alert she didn't notice it at that time, but being back at the base an intense chest pain started. She collapsed, fell, and was heavily bruised. She suffered from nervous palpitations and strong chest pains, spreading from her chest to her throat. She was admitted to the role-2 hospital, scans were taken, without any signs of fractures. She was diagnosed with a non-specific costosternal pain. Morphine was given and they decided to repatriate her. The flight surgeon was not sure if air transportation would be safe for her, so additional painkillers were given. In retrospect, she was uncomfortable that pre-safety procedures had not been followed correctly. The men who accompanied her had appeared nervous. During the visit they had taken off their protective gear and went outside the house. This had made her fearful. At the hospital she was in so much pain that again she collapsed. She was repatriated. At the airport at that moment were a few rocket attacks. Upon arrival in the Netherlands only her husband was on the airport, nobody from the medical team or the Dutch Army was present to pick her up and guide here to the Military Hospital. She went there herself, was assessed, put on painkillers, and sent home. In the absence of followup she continued taking the painkillers. Her commander told her to come back to work when everything was all right. She felt she was left alone. She continued to be worried about the pain. Very little was done to get her back to work. A proper diagnose was lacking. She started to suffer from addiction to pain medication and started physical therapy with very little result. Her symptoms became worse, now spreading out to her whole body. She felt a stiffness of her body, suffered pain in both her feet, had difficulties walking the stairs, had swollen fingers, pain in her right clavicle bone, neck pain, and shoulder pain. The stiffness and pain contributed to making her feel fatigued.
Her cognitions about her symptoms were that she thought her vest had been too tight. In her family there were some rheumatic diseases and she was examined by a rheumatologist and rheumatic diseases were ruled out, but this did not relieve her. Emotionally she was upset that the army had not given her proper material and that safety instructions had not been carried out properly during her last trip. Having arrived at the airport with no pick up and no proper reintegration schedule from work, she felt alone and as though she was not being taken care of.

She started to become frustrated that the pain did not dissipate by itself. She had always been an active woman. She started to be hopeless but wanted to keep strong. She did not want to give up. In her coping she avoided physical exercise since this made her symptoms worse. She also noticed that she was negatively affected by stress. Her breathing was superficial and her muscles tight. She was still taking care of her household; she would not give that away. Her social system, including her husband, started to become worried. At the assessment she was not on sick leave; all of her energy went into her working day. She did not want to fail in her job. In her character she was described as a perfectionistic and active person, who liked to be in control.

\subsection{Case 2}

Patient is a 54-year-old sergeant, who had served the army already for 30 years. He had been deployed 6 times: to the Gulf, Iraq, twice to Bosnia, Kosovo and Uruzgan during his career. In several deployments, he was exposed to situations of high threat and deadly violence. He had been in many dangerous operations himself but was never injured. In his role as a medic he had witnessed several atrocities, had been near explosions and shootings, and had seen many people die. Since 2000, he reported he suffered from physical pains, which gave him a lot of distress. His body hurt; mainly he had pains in his joints. He consulted several medical specialists in the hospital, yet no somatic diseases were found. In 2007 he was sent to a psychiatrist for the first time, in particular since he persistently attributed his symptoms to having been exposed to Sarin gas, pyridostigmine, multiple vaccinations and depleted uranium and there we no further options in the somatic area. Though he had witnessed several traumatic incidents he was not diagnosed with PTSD. He received trials of medication such as benzodiazepines, SSRIs, and pregabalin of which only du- 
loxetine gave some relief, yet with only partial effect. He was guided in his desire to seek help in alternative medicine. His muscle stiffness and pains had set a pattern of physical therapy twice per week for the last years. He was described as a man with high loyalty towards his employer and is very sensitive to authorities. He scored negative on depression and anxiety. He was perceived as rigid in his thinking, never shared anything about his deployments with his wife or children, and wanted to keep them away from his experiences. Though he suffered much, he has skipped only a few days from work. A medal of honor that he applied for, was turned down, which he felt as a great rejection. He blamed the army; he persisted to refer to his pains to being exposed to Sarin during his deployment. When he was admitted to our specialized program for screening he shared with us that he could not have PTSD because he was a soldier and everything he did or saw was part of the job. Also, two years before his retirement he disclosed this to the researchers that he feared retirement. Since he did, he was afraid of losing the health benefits that kept him doing his job so far.

\section{Research in Dutch cohorts}

Netherlands Armed Forces is confronted with soldiers and veterans who after deployment report MUPS that demand medical attention and care. For the Dutch situation these symptom complexes have been reported after deployment to Desert Shield/Desert Storm, UNTAC (Cambodia), and UNPROFOR (Lukavac, Bosnia), as well as Dutchbat (Srebrenica). In many cases a pathophysiological substrate is not found after careful diagnosis $[9,10]$. The symptoms are usually attributed to the deployment(s) because they arose a shorter or longer time afterwards. They do not respond to reassurances or forms of classical symptom management and can develop into a chronic disease with severe functional limitations, resulting in disability. An accurate estimate of the incidence is difficult. In a group of 2700 Cambodia veterans at the VU Amsterdam and the University of Nijmegen, extensive research was performed into possible causal factors of unexplained health problems [11].

Microbiological, immunological, toxicological and vaccination studies yielded no evidence for causes that could explain the symptoms. However, a relationship was found with the daily activity level, exercise tolerance, and psychological functioning, in particular lack of low self-efficacy, somatisation, and negative social interactions.
Recently, a study into the general health of veterans from Lebanon was performed through a written survey. A total of 1835 veterans responded. These patients, 25 years later, still scored above the average standard complaints in the MUPS and PTSD spectrum [12]. The health perception in general was lower than the average standard for a similar group. This can partly be explained by a response bias. At the same time this can indicate that if there are health problems, these can be protracted.

\section{Symptom presentations}

MUPS in soldiers can be seen as a symptom complex without organic basis. As has been reviewed here, the complaints include chronic fatigue, joint pain, pain (head and spine), painful muscles and joints, vertigo, skin irritation, sore throat, symptoms of the respiratory or gastrointestinal tract, arousal (alertness, but also increased sweating), sexual problems, sleep disorders, memory/concentration problems, and others. These complaints result in functional limitations, disability, and reduced quality of life. In the phenomenology there is a strong resemblance with the chronic fatigue syndrome $[13,14]$. The first case presented had similar features as in the early descriptions of $\mathrm{Da}$ Costa's syndrome. The symptoms are predominantly physical in their presentation. From a psychiatric perspective there are similarities with comorbid symptoms found in patients with PTSD, atypical depression, hypochondriasis, undifferentiated somatoform disorder, somatoform disorder with autonomic dysfunction, and with a pain disorder. Differential diagnosis always needs to be made to exclude these disorders. There are also descriptions in the literature with characteristics such as migraine headaches, unexplained abdominal discomfort, and multiple chemical sensitivity $[15,16]$, which the second case demonstrated. Cognitive disorders (attention and memory) and mixed anxiety and mood disorders [17] are also frequently mentioned.

Both medically unexplained symptoms, in general, and among soldiers after deployment, in particular, express often loss of function that is disproportionate to the findings at physical examination, diagnostic, and inconsistent with laboratory findings. Often it is thought that these people are out on secondary gain. An association with stress and psychosocial factors is assumed [14], but has not been systematically investigated. Many patients have a long and complicated history with several consultations in primary and 
secondary care specialists. Several studies or interventions have occurred without conclusive results. In the Netherlands the term 'somatic fixation' has been common practice [18]. In this perspective the patient is convinced that there is something wrong with him/her and often has a specific attribution for the complaints. The symptoms often refer to different organ systems. The course of the disorder is chronic and is associated with, or leads to, impairments in social, interpersonal, and system interactions. Given that, the physical presentation is not primarily thought to be a psychological or psychiatric attribution of symptoms, which frequently in hindsight it appears to be the case.

It is important to note that these physical complaints and reports are typically outside the purview of psychiatry. They are manifest in general practice, general physicians, and further to medical specialists such as neurology, internal medicine and orthopedics, as well as in cardiology, pulmonary and ENT. Sometimes there is also resistance to a descriptive psychiatric explanation for the symptoms.

\section{Development of blended care program for MUPS}

In a ministerial report that was written after studies in veterans that were deployed as part of United Nations Transitional Authority Cambodia (UNTAC) Cambodia [1], recommendations were made with regard to health care programs. Veterans with ill-defined medical complaints after deployment would submit to a detailed integrative medical plan tailored to the individual. The symptoms or complaints could not directly be traced back to a medical and/or psychological component in all cases. Nevertheless, recommendations were made to investigate these complaints seriously. If no medical explanation could be found, a clear course needed to be followed. It was advised that nurturing cognitive behavioral treatment needed to be an important aspect of the program [1, p. 6]. An 'overall plan' should contain synchronized medical as well as psychological help with the support of the social system, as well the physical rehabilitation (fitness), and the return to work (reintegration).

The Central Military Hospital (CMH) together with Military Mental Health (MMH) and Military Rehabilitation Center (MRC) translated the recommendations of the Tiesinga Committee into a blended care specialized program. The aspects of the program developed were derived from various sources, such as men- tioned above, and the available literature on MUPS. This literature focused on treatment strategies in the context of the Gulf War syndrome, in which interventions in the field of physical activities, effort, and psychology were emphasized [19]. This has led to a treatment model that is operated in an outpatient setting, for a period of 4 months (12 weeks) in day treatment. The treatment was designed as closed group therapy, in which six to eight participants per module could participate. The program was designed for each individual to: 1) maximize awareness of symptoms 2) maximize awareness of factors that prevent reduction of symptoms; 3) maximize successful coping with persistent and disabling physical symptoms; 4) obtain a consistent, primary care-based follow-up plan; 5) recognize and address psychosocial contributors to symptom-based disability; 6) improve relationships with health care providers and significant others; 7) reduce excessive and potentially harmful use of the health care system; 8) initiate a program of physical activation that takes into account an individual's unique musculoskeletal limitations; and 9) improve understanding of the known health consequences of the military profession. The treatment program consisted of a day program, one day per week for 12 subsequent weeks and contains of a blend of therapeutic approaches centered around functional rehabilitation: $50 \%$ specialized physical therapy, $20 \%$ cognitive behavior therapy (CBT), 10\% psychomotor therapy, $10 \%$ health education, and $10 \%$ case management. Health education consisted of seminars provided by various specialists. The case manager linked the separate therapies during the day and monitored the general needs of the patients.

The term 'blended' refers to the notion that there is no competition in the treatment strategies of the participating therapists. All participating therapies blend in the service of the benefit of the patient. This is achieved and maintained in frequent multidisciplinary encounters. All therapies refer to a context of healing.

\section{Outpatient day treatment program}

It is important to once more note that MUPS is a working diagnosis only. Despite the acronym MUPS, one should not assume that this is a specific diagnosis or disorder. There is also no golden standard assessment for MUPS. Medical screening is preferentially performed by a family physician who may act in concert with a team of medical specialists, including, 
neurologist, internist, psychiatrist, rehabilitation specialist, cardiologist, ENT doctor, and clinical psychologist regarding diagnosis and need for additional provisions/operations.

The day treatment program was launched in 2009. First, the patient is seen at the outpatient clinic by the family physician and if indicated by other medical specialist (once) for additional research. During the intake the history of the physical complaints is documented in the patient's own words. Detailed medical history is collected from previous consultations and reviewed on course, consistency, completeness, and how systematic it is. This assessment is done to find a somatic basis or explanation for the reported symptom complaints. Indeed, only if this basis is lacking, a patient may be referred to the outpatient treatment. At this time, other physical causes of illness are also ruled out.

A willingness to participate in a constructive way is then explored with the person. It will focus on attribution, perception, coping, body image, ego-strength, and ability to self-reflect. Also, an analysis is made on the meaning of this in the family situation. Additionally, the patient's partner preferably participates in the intake and periodically throughout the treatment. We examined whether patients are able to take responsibility for their complaints to investigate and to find ways to reduce or to modify them. Relative contraindication to our treatment are on-going diagnostic efforts into a medical explanation for the symptoms (i.e., research into a pathophysiological substrate), an insurance procedure in relation to these complaints (progress of the treatment could be affected), severe psychiatric problems, such as depression, psychoses/delusions, addiction, obsessive-compulsive disorders, anxiety disorders, and behavioral or personality disorders. Also a highly disordered (illness perseverant) home system could prevent healthy development. Based on these questions, additional assessment may be indicated. When the diagnosis is complete and adequate, the patient is discussed in a consensus meeting with the whole team. The following topics are important:

As a minimal set, the following factors must be assessed:

- Do co-morbid disorders such as mood/anxiety disorders, PTSD, and depression play a role?

- Are there objective somatic disorders?

- Are there any pre-existing conditions?

- Are there any predisposing factors?

- Are there any illness-perpetuating factors?
- Are there stressors in the private and/or work environment that are important?

- Do physical complaints or limitations exist?

- Has there been adequate therapy/counseling (not only insightful therapy)?

- What has thus far been the primary focus of the treatment?

- According to this treatment, what have been the main obstacles to recovery?

We chose to be stationed at the front door of the general hospital, rather than within the walls of the mental health care unit. We made this choice based on the fact that MUPS is neither fully somatic nor fully psychologically explained. In addition, soldiers who come back from combat usually have difficulties seeking medical care for mental problems, are fearful of stigma and perceive barriers to care [20]. Therefore, we formed a multidisciplinary team comprised of individuals with a variety of medical disciplines. The team consisted of two general family physicians, a psychiatrist, two psychologists/psychotherapist, a psychoeducative nurse, behavioral therapist and a neurologist. The program had two elements: 1) diagnostic assessment, and 2) treatment.

\subsection{Assessment}

During intake and initial assessment, the interviewer checks the somatic field as well as the fields of cognition, emotional, behavioral and social, according to the SCEBS (somatic, cognitions, emotions, behavior, social system) communicative, model. When a patient is likely to have MUPS, he or she is seen for a meeting with the physiotherapist and psychologist of our team. The GP's at the outdoor clinic also offer guidance to medical healthcare workers who seek advice for MUPS issues.

The physiotherapist is consulted if a patient is fit to participate in the program, and a psychologist of the team assesses if the person is cognitively fit and wellsuited from a personality perspective being admitted to group therapy. Any major psychiatric disorder should be also ruled out. Notably, MUPS is associated in 30\% with anxiety and or depression. When a patient is seen by these professionals, the team as a whole gathers and makes a decision as to whether inclusion is justified for this patient.

\subsection{Treatment}

Previous studies showed that physical exercise in combination with body awareness and CBT could be 
effective in those suffering from unexplained physical symptoms [21].The treatment program for MUPS consisted of 12 days of group therapy, once a week. Group therapy proved to be effective [22]. We chose to offer multidisciplinary treatment, which we call blended care. It is based on the 'protocol of treatment for patients with MUPS' by Speckens et al. [23]. This protocol offered guidelines for treatment for MUPS with CBT and graded exercise. Based on participants' needs, it leaves time in the program for different modules, i.e. relaxation, psychomotor therapy, EMDR, and psycho education. Furthermore, we used the Dutch Multidisciplinary Guideline for medically unexplained symptoms and somatic disorders 2010 [24]. We also used recommendations from treatment programs for somatoform and somatoformlike disorders and the stepped-care guidelines for evidenced-based treatment [25].

\subsubsection{Specialized physical therapy}

Physical exercise is based on a model of allostatic load awareness (ALA). This is based on the model of allostatic load by McEwen [26], in which a balance (homeostasis) has been established against a price, of an altered 'set-point' (allostasis) (e.g. high blood pressure, headache, fatigue etc.). Members learn how to exercise while becoming aware of the load that their body takes in a playful interactive way. Patients often experience their bodies as 'heavy', or move beyond their physical limits and ignore body signals and limitations. This takes a toll on body reserves. When they feel good they 'overreact', for which the next day they pay the price of pain or exhaustion. Others were afraid that they could harm their bodies. They ended up in a spiral of inactivity and develop a loss of physical condition.

\subsubsection{CBT according to the 'Model of causes'}

We work according to the 'model of causes'. This model is a kind of CBT but the focus is put not on the physical complaint itself, but the effects in daily life resulting from these physical complaints. The model and its therapeutic implication provide a tool to focus on improvement of daily life and general feeling of the patient. The improvement in activities that the person assumed he could not perform anymore and the focus on abilities rather than disabilities ensures positive reinforcement. Usually health complaints diminish secondarily in response to reengaging in these activities.

\subsubsection{Psychomotor therapy}

This is an intensive training that confronts the participants with their subtle bodily signals and how these are related to their emotions and cognitions. It is an experimental treatment which uses non-verbal methods. Central approach in this is that the patient learns to become aware of the connections between emotions and physical signals.

\subsubsection{Psychoeducation}

In this part researchers offer different educational modules (e.g. education about work and health), communication with the general physician, 'taking care of yourself', and working on your social environment. Sessions last approximately an hour and are interactive.

\subsubsection{VIP}

At two times during the program there is a so-called VIP day were the spouse or another important person of the patient also takes part in the program. This allows the team to collect information about the social system, and also allows the VIP an appreciation of the intensity of the treatment.

\section{Therapeutic course in blended care program}

\subsection{Case 1}

During therapy the soldier learned during sports and play not to be afraid to move and make movements slowly and smoothly. We encouraged her to make 'big' movements, so her body would be relaxed and her body language would be open. During CBT, according to the model of causes, we showed her that doing everything on her own while having many symptoms would make her tired. This was manifested in tense muscles with intense pains, but the more she tried, the less it worked. The team taught her to take brief breaks and rest at discrete moments during the day, to relax, and to let go. If she would learn how to relax her muscles, she would be less tense and experience less pain. During psychomotor education, we explored her emotions at different points throughout the education process. She learned that her muscles would tighten when she feels angry and insecure, and relax if she is not angry. During psychotherapy we focused on letting the anger and insecurity out. The circle she was stuck in consisted of "being angry or insecure - tighten muscle - muscle pain and stiffness - not being able to do the things she 
wants - angry about not being able to do the things she wants - tighten and so on." She gained insight in the fact that already before deploying she felt unsafe and insecure. During specialized physical therapy she found out that the stiffness and pain of her muscles reminded her of the horrible trip in the car. She was aware that her complaints were a physical reminder of a stressful experience. After the 12-week treatment, her complaints were fully gone, and she was maximally aware of her boundaries. She could feel when she had to stop and take a rest. She knew that regular physical exercise would keep her body relaxed and in shape. She could put her complaints in a framework of cause and effect. To let go of her anger against "the army" she wrote a letter to a high commanding officer. He replied. This gave her satisfaction and made her feel at ease. In a six month follow up after treatment, she was back to work full-time.

\subsection{Case 2}

The officer learned during playful group wise physical exercises that he could do more than he was aware of and that this did not negatively affect symptoms. During physical therapy, he also discovered that being part of a group could be quite fun and that the group could be supportive in times of need. He found much support and started to share his thoughts and feelings. It was good for him to know that, being a soldier, experiencing emotions would not make him less appreciated. During the CBT, which was based on the model of causes, he learned that the pain he felt in his body was a pain he could not express in emotions. Because he always focused on his physical complaints, everybody was focused on his physical symptoms and not on his mental pain. Psychomotor therapy had taught him that his pain actually was, in part, mental imprints that he had been very afraid to feel. When slowly during therapy some physical complaints started to change, his symptoms shifted: he started to have nightmares and flashbacks of previous deployments. He felt an urge to talk about experiences that he never disclosed to anyone. It was two months before his retirement. His diagnosis changed to PTSD in conjunction with chronic pain. He blamed himself for not earlier disclosing his experiences during deployment. He noticed that physical complaints came when mental pain was not accepted. After completion of the day treatment, he continued with narrative exposure therapy in which his wife was also involved. After day treatment, he had developed delayed onset PTSD.
These vignettes demonstrate the clinical course of participation in a blended care, multidisciplinary treatment program. Central in the program is the notion that a context is created in which healing is facilitated. Sometimes this leads to identification and amplification of factors that contribute to successful coping (see case 1), but in other cases (case 2) this is only first realized after breakdown of maladaptive coping.

Since the start of 2009, a total 160 soldiers have been admitted to our specialized program. Of this group, 68 followed the day treatment program, which was divided into nine groups over the course of three years. Of the 92 that were not admitted to the program, 44 received another diagnosis, among which are gastric ulcer, Epstein Barr infection, and auto-immune disease. Twenty received a psychiatric diagnosis, mostly depression, hypochondria, or anxiety disorder. The remaining group of 28 was not admitted because they did not meet inclusion criteria. We gave patients in this group personal counseling. Some patients did not participate because of other reasons (e.g. some left the army, some felt well for no reason, or developed another illness).

We then looked at medical consumption and work recovery as means of functional impairment. We checked the files of the primary healthcare of the patients. All patients gave signed permission to look at their files. We included the doctors' visits they made three months prior to treatment and three months after treatment. If the amount of visits was lower, we called this less medical consumption. We also checked if three months prior to treatment there was sick leave and the percentage of sick leave. We checked after treatment how many of those with sick leave had returned to work full time. The participants were also tested on physical complaints, coping, and personality.

A total of 68 patients entered and completed the 12 -week program. For $69 \%$ of them, their physical symptoms had fully receded. Medical consumption was counted three months prior to treatment and three months after treatment. Before day treatment, a number of consultations in three months was average 3,8 (0-9). After day treatment had dropped to $1,7(0-5)$.

From the total of 68 patients, 41 were on sick leave before treatment, 20 had short sick leave (defined as three periods of three days sick leave in three months) and 21 had continuous sick leave. After treatment, 28 had a full work recovery without sick leave and only few had a period of short sick leave. One had no recovery and two had left the army. Three patients who were not military fit before treatment were considered military fit after medical re-evaluation after the treatment. 
On qualitative assessment, overall, the patients felt happier, less frustrated, and physically and mentally more fit. Also their spouses and support systems were more satisfied with their lives than before. Of importance, there were no claims whatsoever against any of the workers at the program or at the outdoor clinic in general. Overall they were satisfied that their employer gave them the opportunity to get better.

\section{Conclusion}

As is outlined in this paper a program that is based on a blended care, multidisciplinary 12-week day treatment approach has a beneficial value on the outcome for patients with MUPS, in particular on quality of life and overall functional improvement. A limited program like the one we offered (total number of treatment days is 12) gives patients time to work on different parts of the negative spiral they are in. We cannot avoid that sometimes patients, as different as they are, do not fit into our traditional healthcare system. For these people, a blended, multidisciplinary treatment program as described can make a difference. The additional effect of the group for support and sharing experience and attention was an added benefit. It provides awareness for their high allostatic load and opportunities to modify.

Understanding MUPS and other ill-defined medical conditions and the necessary ingredients for successful treatment is still in its infancy. The following themes and questions could play a role in future studies: 1) What factors influence improvement, and are these factors integrated in the treatment? 2) Is there an optimal activity level for patients with MUPS for optimal physical function and participation and what is the role of physical activity and its influence on the symptoms? 3) What are the long-term effects of the current treatment program and is a follow-up trajectory needed for more enduring effects? 4) If the answers are known and positive, what should such a trajectory consist of? 5) What is the most optimal composition of the multidisciplinary elements? It could be that the current elements can be optimized or that other disciplines need to be involved. This also applies to the duration and intensity of the treatment program. Finally, cost effectiveness should be examined in more detail.

Incidentally MUPS are observed in veterans who do not meet all criteria for PTSD [27]. The causal relationship between many physiological abnormalities in PTSD patients and perceived stress load has been confirmed in animal models [28]. Besides some basic changes herein, a picture of generalized hyperresponsiveness of physiological systems can be seen that may potentially contribute to physical complaints. Not only the external (stress) load plays a role, but also the individual vulnerability (e.g. as a result of traits or experiences earlier in life). Parameters of functional impairment-oriented research are: general physical health, general health history, and medical history including personality and temperament, neuroendocrine, cardiovascular, gastrointestinal and immune functions, in addition to a test for sensitivity.

Future research will have to increase the understanding of the nature of this diagnostic 'category.' The homogeneity of the symptom complexes now is the first point of attention. Not infrequently has a post-deployment syndrome gradually developed into a recognizable PTSD or other disorders within mental health spectrum. Professionals would be well advised to look for common elements, i.e. problems in impulse control and psychophysiological hyperreactivity [29]. Such properties may have been acquired but may have started in early childhood became strengthened during service. Such insights will in turn clarify the therapeutic potential and hopefully expand it as well. This means that extending clinical treatment to scientific evaluative research, as was already recommended by the Tiesinga Committee in 1999, is essential.

We live in an age in which people scrutinize their health and the health implications of the workplace to a very high degree. As we outlined a program that is providing health care for people deploying to unpredictable, traumatic, and potentially toxic environments, we must prepare to implement coordinated, multidisciplinary medical evaluations for those. We described as framework for a program that is executed in a team-based setting that allows the patient to feel understood, warrants job satisfaction, and could be costeffective. Such a treatment is to be innovative, timely, and provides effective personalized health care to those with persistent ill-defined post-deployment physical symptoms.

\section{Acknowledgements}

We would like to thank the MUPS team for their contribution to this manuscript: $\mathrm{C}$. van der Velden-de Boer, MD, AO R. Alleman, COL F. van der Meer, LCOL P. Venhovens, CAPT J. Visser, CAPT F. van Londen, B. Carki, MSc, O. van der Meij, MSc, D. Dijkman, MSc. 


\section{References}

[1] Commissie-Tiesinga. Rapportage Begeleidings Commissie Post Cambodja Klachten Fase II, 12 December 2000.

[2] Vries M de, Soetekouw PMMB, Meer van der JWM, Bleijenberg G. Natural course of symptoms in Cambodia veterans: A follow-up study. Psychol Med 2001; 31: 331-333.

[3] Engel CC, Hyams KC, Scott K. Managing future Gulf War Syndromes: international lessons and new models of care. Philosophical Transactions of the Royal Society B 2006; 1468: 707-720.

[4] Barrett DH, Gray GC, Doebbeling BN, Clauw DJ, Reeves WC. Prevalence of Symptoms and Symptom-based Conditions among Gulf War Veterans: Current Status of Research Findings. Epidemiological Reviews 2002; 24: 218-227.

[5] Vermetten E, Linn FHH. 2008. Onbegrepen klachten bij militairen na uitzendingen. Bijblijven 2008; (8): 55-62.

[6] Gulden van der JW. Onverklaarde chronische klachten. Houten: Bohn, Stafleu van Loghum, 2006.

[7] Olde Hartman T, van Ravesteijn H, Lucassen P. Onverklaarde lichamelijke klachten. Huisarts \& Wetenschap. 2012; 55: 301305.

[8] Thomas S. Dealing with medically unexplained symptoms in general practice: from irritation to "the tricks of the trade". Abstract. Netherlands Tijdschrift Geneeskunde 2006; 150: 657-9.

[9] Mulder YM, Reijneveld SA. Gezondheidsonderzoek UNPROFOR. Een onderzoek onder militairen die uitgezonden zijn geweest naar Lukavac, Santici en Busovaca. (BosnieHerzegovina) in de periode 1994-1995. Leiden: TNO Preventie en Gezondheid, 1999.

[10] Soetekouw PM, Vries de M de, Preijers FW, Crevel van R, Bleijenberg G, Meer van der JWM. Persistent symptoms in former UNTAC soldiers are not associated with shifted cytokine balance. Eur J Clin Invest 1999; 29(11): 960-3.

[11] Vries de M, Soetekouw PM, Meer van der JWM, Bleijenberg $\mathrm{G}$. The role of post-traumatic stress disorder symptoms in fatiqued Cambodia veterans. Mil Med 2002; 167(9): 790-4.

[12] Mouthaan J. Libanon, 25 jaar later: Het laat ons nooit meer los. Veteraneninstituut, Interne Publicatie, 2005.

[13] Aaron LA, Buchwald D. A review of the evidence for overlap among unexplained clinical conditions. Ann Intern Med 2001; 134(9 Pt2): 868-81.

[14] Henningsen P, Zimmermann T, Sattel H. Medically unexplained physical symptoms, anxiety, and depression: A metaanalytic review. Psychosom Med 2003; 65(4): 528-33.

[15] Nisenbaum R, Barret DH, Reyes M, Reeves WC. Deployment stressors and a chronic multisymptom illness among Gulf War Veterans. J Nerv Ment Dis 2000; 188: 259-266.

[16] Reid S, Hotopf M, Hull L, Ismail K, Unwin C, Wessely S. Multiple chemical sensitivity and chronic fatique syndrome in
British Gulf War veterans. Am J Epidem 2001; 153: 604-609.

[17] David AS, Farrin L, Hull L, Unwin C, Wessely S, Wykes, T. Cognitive functioning and disturbances of mood in UK veterans of the Persioan Gulf War: A comparative study. Psychol Med 2002; 32(8): 1357-70.

[18] Grol RPTM. Huisarts en somatische fixatie. Bohn, Scheltema \& Holkema, 1983.

[19] Engel CC, Roy M, Kayanan D, Ursano R. Multidisciplinary Treatment of Persistent Sympoms after Gulf War Service. Mil Med 1998; 163: 202-208.

[20] Hoge CW, Castro CA, Messer SC, McGurk D, Cotting DI, Koffman RL. Combat Duty in Iraq and Afghanistan, Mental Health Problems, and Barriers to Care. The New England Journal of Medicine. 2004; 351-1: 13-22.

[21] Donta ST, Clauw DJ, Engel CC, Guarino P, Peduzzi P, Williams DA, Skinner JS, Barkhuizen A, Taylor T, Kazis LE, Sogg S, Hunt SC, Dougherty CM, Richardson RD, Kunkel C, Rodriquez W, Alicea E, Chiliade P, Ryan M, Gray GC, Lutwick L, Norwood D, Smith S, Everson M, Blackburn W, Martin W, McLeod Griffiss J, Cooper R, Renner E, Schmitt J, McMurtry C, Thakore M, Mori D, Kerns R, Park M, PullmanMooar S, Berntstein J, Herschberger P, Salisbury DC, Feussner JR, for the VA Cooperative Study \#470 Study Group. Cognitive Behavioral Therapy and Aerobic Exercise for Gulf War Veterans' Illnesses. The Journal of the American Medical Association. 2003 ; 19: 1396-1404.

[22] van Schaik E. Effective Grouptraining for patients with unexplained psychical symptoms; A randomized controlled trial with a non-randomized one-year follow up. PloS ONE. 2012; 7: 426-29.

[23] Speckens AEM, Spinhoven Ph, van Rood YR. Dutch Protocol treatment of patients with unexplained medical physical symptoms: CBT.

[24] Trimbos Instituut/Netherlands Institute of Mental Health. Addiction. (Multidisciplinary guidelines medically unexplained symptoms and somatoform disorders). Houten: Ladenius Communicatie, 2010

[25] Rood van YR. Treatment program somatoform and somatoform-like disorders. Stepped-care guidelines for an evidenced-based treatment, 2007.

[26] McEwen BS, Wingfield JC. The concept of allostasis in biology and biomedicine. Horm Behav 2003; 43(1): 2-15

[27] De Loos WS. Somatic war syndromes: no man's land between the trenches? Eur J Clin Invest 2000; 30: 566-569.

[28] Stam R. PTSD and stress sensitisation: A tale of brain and body. Part 2: animal models. Neurosci Biobehav Rev 2007; 31 (4): $530-57$

[29] Vermetten E, Loos de W. Medisch Onbegrepen Lichamelijk Klachten bij Veteranen; het Post-Deploymentsyndroom, diagnose en zorg in ontwikkeling. Veteranenbundel, 2004, pp. 5163. 